\title{
General Discussion to the two preceding Papers of A. Scher and I. Perkash
}

Dr KRISHNAN (G.B.). Dr Scher, your picture of trying to do the retrograde and getting a picture with a lot of exudation of the contrast media: you will be interested to know that we have been having the same trouble and we have at last found that the little suction cup used by the gynaecologist when doing a hysterosalpingogram is eminently useful to do this job. You put the little cup in and produce a little vacuum by an ordinary bicycle pump and you can carry on doing any retrogrades you want so long as you don't keep it too long and get a phimosis of the glans penis. But my main question is to Dr Perkash. I was interested in two things. In one particular case he mentioned that on urodynamics with alpha blocks he found that there was no reduction in the sphincter activity and he did the bladder neck resection but ultimately had to resort to recatheterisation and the patient had gone home. I would like to ask him why he did that and why did he not consider an external sphincterotomy at the same time because after all the sphincter neck resistance there was the obvious outlet obstruction.

Dr Perkash. I think I did mention that that patient was already recovering. It was 6 months post-injury and the patient had refused sphincterotomy because he was expecting, as the belief is, that he may recover and he wanted to go and catch some salmon way up in North Seattle. I hope he is going to come back and get his sphincterotomy done and get the catheter removed.

Dr Hussein GolJi (U.S.A.). I'd like to discuss a lot of gadgets which we are using in Long Beach VA Hospital for doing retrograde urethrography like Dr Scher. I am wondering if he has ever used any infusion pump which is controlled by a safety valve attached to a clamp to do a retrograde urethrography. This is under study and the paper concerning this matter is going to be published. However, the cysto-urethrography by I.V.P. has been very dissatisfactory to us and this procedure has been adopted for doing retrograde urethrography. The Brodnic clamp is being attached to the meatus and is also attached to an infusion pump along with a safety valve which opens up whenever intra-urethral pressure goes higher than I 50 centimetres of water. At the same time I'd like to mention that intact urethral mucosa can stand a pressure up to 250 centimetres of water without being ruptured. Therefore, the safety valve which is attached to the Brodnic clamp is a safety measure to prevent rupturing the urethra and extravasation that $\mathrm{Dr}$ Scher has been complaining of. Dr Perkash has been very lucky in controlling the infection in paraplegic patients. I have discussed this problem with other colleagues and it seems that Dr Perkash has been having good luck with treatment of the infection in the patients even having a year, 2 years or 3 years catheter drainage, and he has sent them home free of infection. I was wondering first, when we say infection-free patients, does that mean clinical infection or laboratory infection?

Dr Perkash. No we don't mean clinical and I gave the criteria already.

DR Golgi. Now I'd like to hear from other colleagues especially Dr Rossier what amount of luck he has had with the treatment of the infection in these patients to send them home free of the infection as a whole.

DR MICHAELIS (Chairman). Ladies and gentlemen, may I just make a basic observation. There is a difference between papers read and questions asked. Papers should be short, questions should be very much shorter.

DR G. HAHN (Canada). I was interested in your comment on the use of dantrolene sodium. I missed your indications for the use of this drug. Just one comment: in this city some of us are concerned about the potential of induction of seizures whilst using this drug. I would like to hear comments from others who may have had this experience. DR HARDY (G.B.). We did at Lodge Moor some of the original trials on dantrolene sodium and I was under the clear impression that it didn't have any action on the bladder.

DR KRISHNAN (G.B.). In our experience in Southport, where we dealt with dantrolene sodium, it really didn't have any effect on the skeletal muscles either. Our impression has been extremely unsatisfactory and I was very interested to hear Dr 
Perkash's view of dantrolene sodium having anything to do at all with bladder musculature or bladder outlet musculature.

Dr Perkash. We will be presenting an exclusive series on the EMG activity of the pelvic floor in course of time before and after using dantrolene sodium. We have been very lucky to such an extent that we could almost abolish pelvic floor motor unit activity in these patients, and with enough follow up we'll be publishing within the next 6 months or so.

DR P. Dollfus (France). First question to the first speaker. Have you had any experience of iced water cystograms to study the internal sphincter activity? Second question to Dr Perkash, what is your acceptable residual urine in your beautiful series of sterile urines and third do you, Dr Scher, have any notion of direct external sphincter infiltration by local anaesthetics, I mean Xylocaine. I think that the general population didn't really understand what you were injecting into the internal sphincter, if you could clarify that or get somebody to clarify it.

DR SCHER. As regards the iced cystogram technique we have used this, freezing the contrast. It does appear to facilitate the examination, and it does seem to be useful but I don't think it is particularly useful in those patients who cannot void. It seems to give a slight advantage but is not to me particularly impressive.

Dr Perkash. Residuals varied between 100 to $250 \mathrm{cc}$, so less than $100 \mathrm{cc}$ most of the time. 